\title{
DETECCION MEDIANTE PCR-RFLP DE Fusarium oxysporum f.sp. fragariae AGENTE CAUSAL DE FUSARIOSIS EN FRUTILLA
}

\author{
(Detection by PCR-RFLP of Fusarium oxysporum $f$. sp. fragariae causal agent \\ of fusariosis in strawberry)
}

\author{
Francisco J. González*\#, Stephanie Walls**, \& Marcela Mancilla*\# \\ *Laboratorio de Biología y Genética Molecular, Escuela de Medicina, \\ Universidad de Valparaíso; \#Laboratorio Gendetect Ltda.; \\ **Programa de formación «International Bachelor Degree» UK- Saint Margaret School.
}

Palabras clave:Fusarium oxysporum f.sp. fragariae, PCR-RFLP, factor de elongación 1-alfa Key words:Fusarium oxysporum f.sp. fragariae, PCR-RFLP, elongation factor 1-alfa

\section{RESUMEN}

La frutilla es una de las frutas de importante crecimiento económico tanto en Chile como a nivel Mundial. Desde hace varios años su producción ha experimentado pérdidas económicas, principalmente a causa de las enfermedades producidas por Fusarium oxysporum f.sp. fragariae (Fof). Este patógeno, se ha propagado rápidamente por casi todo el mundo debido a su difícil diagnóstico y actualmente la única manera de detectarlo es mediante test de patogenicidad, técnica laboriosa que requiere de bastante tiempo y material, lo que dificulta su detección oportuna. Debido a que el diagnóstico genético y las técnicas moleculares son metodologías rápidas y altamente eficaces, el objetivo de este trabajo fue diseñar un método para detectar a Fof, con el fin de controlar y certificar el ingreso o salida del país de este patógeno.

Para esto se amplificó el gen «Factor de Elongación 1- $\alpha \gg(E F 1-\alpha)$, en 25 cepas de F. oxysporum aisladas desde diversas localidades de la VIII región y $R$. Metropolitana, 4 cepas otorgadas por el laboratorio Nacional del Servicio Agrícola y Ganadero (SAG), y 4 cepas patogénicas controles importadas desde ATCC, EE.UU. Posteriormente por digestión con endonucleasas MseI y MspI se logró diferenciar las cepas de Fusarium oxysporum f.sp. fragariae de las respectivas cepas no patogénicas de este hongo. Estos resultados fueron confirmados mediante electroforesis en geles de poliacrilamida denaturante, RFLP con dos endonucleasas y parcialmente mediante secuenciación del producto amplificado de Fof, revelándose de esta manera la eficacia de esta metodología.
ABSTRACT

The strawberry is one of the fruits with important economic growth both in Chile, as on a world-wide basis. For several years, the fruits production has suffered economic losses principally due to the causes of Fusarium oxysporum f.sp. fragariae (Fof) produced diseases.This pathogen has widely propagated around the world, due to it is complex diagnosis.

Actually, the only way to detect them is buy using a pathogenic test, which is a laborious technique that requires a long time and complex materials to effect, which makes an opportune detection difficult.

Since genetic diagnosis and molecular techniques are fast and highly efficient methods, the aim of this work is to elaborate a method to detect Fof, with the aim of controlling and certifying the countries of import or export of these pathogens.

To carry this out, the genetic of Elongation Factor 1- $\alpha(E F 1-\alpha)$, in 25 strains of $\boldsymbol{F}$. oxysporum was separated from diverse areas in the $8^{\text {th }}$ Region and the Metropolitan Region. Plus 4 strains kindly donated by the National Laboratory of Agriculture and Livestock (SAG) and 4 pathogenic control strains imported from ATCC, USA. After digestion with endonucleases MseI y MspI it was possible to differentiate Fof and a strain of Fusarium oxysporum f.sp. lycopersicis from their respective strains of non pathogenic $\boldsymbol{F}$. oxysporum.

These results were confirmed by electrophoresis in denaturant poliacrylamide gels, RFLP with two endonucleases and partially by secuentiation of the amplified product of the Fof revealing in this form the efficiency of the methodology employed. 


\section{INTRODUCCION}

La frutilla (Fragaria ananassa Duchesne) es un cultivo con una creciente importancia comercial en Chile y actualmente alrededor de 1.100 ha han sido plantadas con el fin de satisfacer el consumo interno y a la agroindustria. Esta fruta se propaga en forma vegetativa, empleando plantas de alta calidad, producidas en viveros especializados, y conservadas en frío (1).

Existen muchas «enfermedades de la frutilla», y en Chile una de las de mayor importancia es producida por hongos del género Fusarium, debido a la gran cantidad de variedades y a su amplia difusión en el mundo (5).

Los patógenos de mayor grado de especialización de este género, son los agrupados dentro de la especie Fusarium oxysporum, hongo cosmopolita, el cual puede ser considerado un arma biológica que amenaza la biodiversidad de amplias regiones en el mundo $(2,4,25)$. Este hongo es muy abundante en las zonas templadas y tropicales, es uno de los más fitopatógenos y causa daño a diversas plantas en cultivos, ocasionando distintos tipos de enfermedades tales como: marchitamiento en las hojas, vasculares, pudrición de frutos, incluso la muerte de las plantas. Es decir, gracias a los diversos mecanismos que tiene el hongo para vencer las defensas de muchos hospedadores. F.oxysporum existe en muchas formas patógenas, parasitando a más de 100 especies de Gimnospermas y Angiospermas, que en general invaden los vasos del xilema provocando las enfermedades conocidas como «Fusariosis vasculares» $(2,4)$.

F. oxysporum es una de las especies que presenta mayor variabilidad genética. Esta variabilidad está relacionada con condiciones ambientales, ecológicas, geográficas, y la presencia de un hospedador (5). Existen muchas formas dentro de esta especie, las que se agrupan como formas especiales. La forma especial (f.sp.) corresponde a cepas cuyas características morfológicas y de cultivo son indistinguibles, pero muestran diferentes propiedades fisiológicas en su habilidad para parasitar un hospedante específico. Este taxon se ha empleado para categorizar aislamientos que causan enfermedades de una especie, género o familia en particular $(3,25)$.

Las formas especiales de $\boldsymbol{F}$. oxysporum se han subdividido en razas fisiológicas, con base en su especificidad patogénica sobre determinadas variedades de una misma especie de planta (11).

Actualmente se conocen aproximadamente 120 formas especiales distintas, patógenos de cultivos como el de la papa, girasol, espárragos, apio, col, cilantro, pepinillo, aguacate, clavel, eucalipto, frutilla, gladiolo, soya, uva, calabaza, lenteja, tomates, trébol, camote, remolacha, marihuana, algodón, cebolla, café, berenjena, nuez, tabaco, sandía, tuna, fréjol, coníferas, roble, rábanos $y$ alcachofa entre otros $(6,8,9,10,13,18)$.
Entre éstas se encuentran F.oxysporum f.sp. fragariae, responsable de la enfermedad del marchitamiento vascular producida en las plantas de la frutilla, ocasionando así grandes pérdidas económicas a nuestro país. El marchitamiento de la frutilla fue observado por primera vez en 1965 en Queensland, Australia (17). La rápida propagación de esta enfermedad, se ha debido principalmente a su difícil diagnóstico. Gran cantidad de cepas de F.oxysporum, que habitan comúnmente en los suelos, son saprófitas, las que desde un punto de vista morfológico son indiferenciables de las potencialmente patógenas.

En la práctica el diagnóstico de estas enfermedades se realiza mediante un test de patogenicidad, lo que implica gran cantidad de tiempo y material (17). En los últimos años, el avance de las técnicas moleculares y principalmente aquellas basadas en el análisis de ADN como la reacción en cadena de la polimerasa (PCR), y el polimorfismo de longitud de los fragmentos de restricción (RFLP), han permitido el desarrollo de metodologías rápidas, precisas, objetivas y aplicables a un gran número de muestras para la detección y caracterización de diversos hongos patógenos como integrantes de los géneros Candida, Aspergillus (7), F.oxysporum f.sp. albedinis (4), F.oxysporum f.sp. melonis (19), Fusarium spp. (3), Fusarium asociados a cucurbitáceas (14), F.oxysporum f.sp. canariensis (17).

El objetivo de este trabajo es diseñar y evaluar una técnica rápida y eficiente para identificar $\boldsymbol{F}$. oxysporum f.sp. fragariae, con la finalidad de poder detectarlo oportunamente y así evitar su ingreso o salida de sitios de producción o el país.

Para ello se escogió el gen nuclear que codifica para el Factor de Elongación -1á (EF-1á), el cuál es altamente conservado en el complex Fusarium, pero lo suficientemente variable para establecer diferencias ínter específicas e intraespecíficas (16, 21, 22).

Se plantea la hipótesis que el gen que codifica para el Factor de Elongación 1-alfa, posee la suficiente variabilidad genética para poder establecer diferencias entre distintas especies de F.oxysporum y la f.sp. fragariae.

\section{MATERIALES Y METODOS}

Búsqueda en el gen EF-1á. Para encontrar un sitio que permita diferenciar a F.oxysporum f. sp. fragariae entre las formas no-patogénicas del hongo, se analizaron las secuencias del gen EF-1á de diversas formas especiales de $\boldsymbol{F}$. oxysporum, cuya información se encuentra 
depositada en el GenBank (http://www.ncbi.nlm.nih.gov) bajo número de acceso AF008446-AF008515 (16).

Sin embargo el gen EF-1á perteneciente a Fusarium oxysporum f. sp. fragariae, aún no se encuentra publicado. Para obtener la secuenciación del gen EF1á en esta forma especial, se obtuvo una muestra de dicho patógeno desde la ATCC (American Type Culture Collection). Se procedió a extraer su ADN, amplificándose mediante PCR, observándose mediante electroforesis en gel de agarosa y cortándose cuidadosamente el producto amplificado desde el gel de agarosa y finalmente purificándose mediante el QIAquick Gel Extraction Kit (Este protocolo es diseñado para extraer y purificar ADN de un gel de agarosa en buffer TBE).

Ya purificado y obtenido el producto amplificado se envió a secuenciar a la empresa Polyscience.

Posteriormente, una vez obtenida la secuencia se alineó con otras formas especiales de Fusarium, mediante el programa DNAassist Versión 1.02, estableciendo así las variaciones en el gen de las distintas razas fisiológicas.

Obtención de las cepas. Las diferentes cepas de $\boldsymbol{F}$. oxysporum f.sp. fragariae utilizadas, fueron aisladas de material colectado entre los meses de Diciembre del 2004 hasta Abril del 2005, principalmente en frutillas de semilleros de plantas sintomáticas de exportación, localizadas entre la V y VIII Región. El material colectado correspondió a tejidos de vasos conductores (cuello, corona y tallo) de plantas sintomáticas con fusariosis. En forma adicional se obtuvieron cuatro cepas otorgadas por el laboratorio nacional del Servicio Agrícola y Ganadero (SAG), extraídas desde tomate (2) y frutilla (2). Además, se aislaron cepas de $\boldsymbol{F}$. oxysporum de otros hospedadores, como de humanos y cepas de $\boldsymbol{F}$. proliferatum (facilitado por el Dr. Eduardo Piontelli), y F.oxysporum f.sp. lycopersici (obtenidas de la ATCC, FOL NRRL 36383), para utilizarlo como controles negativos (c-). Como cepa control positivo $\left(\mathrm{c}^{+}\right)$en PCR se utilizó la cepa ATCC 18138.

Aislamiento y mantención de las cepas. Para la obtención de las cepas desde el material colectado, los tejidos infectados se esterilizaron superficialmente en una solución de etanol por $1 \mathrm{~min}$, para posteriormente ser tratados en una solución de hipoclorito de sodio al 5\%, se enjuagaron 3 veces en agua estéril para secar posteriormente en flujo laminar de aire estéril. Los procedimientos utilizados para el aislamiento de Fusarium spp., corresponden a la metodología desarrollada por el Fusarium Research Center de la Universidad de Pennsylvania y la utilizada por el Fusarium Laboratory de la Universidad de Sydney $(15,20)$.

Una vez desinfectado los trozos de tejido conductor, se sembraron sobre medio de cultivo agar papa dextrosa (PDA, $200 \mathrm{~g}$ de papa, $20 \mathrm{~g}$ de dextrosa, $20 \mathrm{~g}$ de agar) y se incubaron a $25^{\circ} \mathrm{C}$ durante 7 días.

Para la identificación taxonómica de los aislamientos se utilizó la metodología de clasificación de Nelson et al. (1983) (26).

Extracción de ADN. Para la extracción del ADN fúngico se utilizó el método propuesto por Liu et al. (12), pero empleando el buffer de lisis de Jaeger et al., (7). Se inoculó micelio proveniente del cultivo de las muestras de las frutillas, en medio Peptona-Dicloran, y luego de incubar de 3 a 7 días se extrajo $1 \mathrm{~cm}^{2}$ de la zona de avance de la colonia.

El micelio se molió en un mortero, para luego ser colocado en un tubo Eppendorf 1,5 mL con $500 \mu \mathrm{L}$ buffer de lisis (200 mM Tris-HCl pH 8,5; 250 mM NaC25 mM EDTA; 0,5\% SDS), dejándose a $\mathrm{T}^{\circ}$ ambiente por $10 \mathrm{~min}$. Luego se añaden $150 \mu \mathrm{L}$ de acetato de sodio $\mathrm{pH}$ 4,8 (60 $\mathrm{mL}$ de acetato de sodio $5 \mathrm{M} ; 11,5 \mathrm{~mL}$ ácido acético glacial y 28,5 mL de agua destilada), el tubo es agitado en vortex y centrifugado a $13.000 \mathrm{x}$ rpm por $1 \mathrm{~min}$.

El sobrenadante se transfiere a otro tubo y se agrega un volumen igual de isopropanol, se mezcla por inversión y se centrifuga a $10.000 \mathrm{x}$ rpm por $2 \mathrm{~min}$. Se descarta el sobrenadante, y el pellet se lava con $300 \mu \mathrm{L}$ de etanol $70 \%$ frío, luego se centrifuga a $10.000 \mathrm{x}$ rpm por $1 \mathrm{~min}$. El sobrenadante nuevamente es descartado y el pellet es secado al aire por $5 \mathrm{~min}$., y resuspendido en $50 \mu \mathrm{L}$ en buffer TE-PCR. (Tris HCl 10 mM, 1 mM EDTA, pH 8,0, estéril).

Electroforesis. Para asegurar la calidad del ADN obtenido, se cuantifica espectrofotométricamente a 260 y $280 \mathrm{~nm}$, y las muestras se corren en una electroforesis en gel de agarosa al $2 \%$ en buffer TBE $1 \mathrm{X}$ (Tris-BoratoEDTA). Se visualizan con Bromuro de etidio al $1 \%$, en un transiluminador a $206 \mathrm{~nm}$ de luz UV.

PCR (amplificación del gen EF-1á). Cada muestra de reacción contiene $13 \mathrm{ng}$ de cada primer, 0,2 U de Taq polimerasa, 0,115 $\mathrm{mM}$ deoxinucleotido trisfosfato, $1,8 \mathrm{mM}$ $\mathrm{MgCl}_{2}, \mathrm{H}_{2} \mathrm{O}_{\mathrm{dd}}, 40$ ng de ADN y un buffer de amplificación (50 mM KCl; 10 mM Tris-HCl, pH 9; y 0,1\% Triton X100) (17). El volumen de reacción final por muestra es de $25 \mu \mathrm{L}$.

La amplificación se lleva a cabo mediante PCR utilizando el siguiente programa, en un termociclador Thermal Cycler (6); 30 ciclos; $94^{\circ} \mathrm{C}$ por $1 \mathrm{~min} ; 60^{\circ} \mathrm{C}$ por 30 seg; $72^{\circ} \mathrm{C}$ por 90 seg; se finaliza con una extensión de $72^{\circ} \mathrm{C}$ por $10 \mathrm{~min}$.

La amplificación del gen EF-1á se lleva a cabo mediante los partidores EF-1 y EF-2 (Tabla 1), 
Tabla 1: Muestra la secuencia y características de los partidores utilizados.

\begin{tabular}{ccccc}
\hline Primer & Secuencia & TM & $\mathrm{N}^{\circ}$ de bases & AT/CG \\
\hline EF-1 & 5’ ATG GGT AAG GAR GAC AAG AC 3’ $^{\prime} 60^{\circ} \mathrm{C}$ & 20 & $10 / 10$ \\
EF-2 & 5’ GGA RGT ACC AGT SAT CAT GTT 3’ $^{\prime}$ & $60^{\circ} \mathrm{C}$ & 21 & $12 / 9$ \\
\hline
\end{tabular}

conservando exones e intrones (Fig. 1), los que fueron adquiridos en Applied Biosystems.

RFLP (Identificación de la forma especial fragariae) . Una alícuota de $10 \mu \mathrm{L}$ del producto obtenido mediante PCR de las muestras se digieren por 2 horas con 2,5 U de la endonucleasa MseI (5'-T*TAA-3'). Adicionalmente, se realizó una segunda digestión con 2,5 U MspI (HpaII), enzima de restricción que comprueba la eficiencia de MseI. La presencia de esta secuencia en las formas patogénicas, genera un sitio de reconocimiento para la endonucleasa, que no poseen las cepas no-patogénicas $(20,22),(*$ indica sitio y secuencia de corte de la endonucleasa).

Electroforesis producto PCR y de RFLP. Los fragmentos amplificados y de restricción obtenidos se separaron por electroforesis en gel de Agarosa 2\% TBE $1 \mathrm{X}$, y se visualizaron con bromuro de etidio al $1 \%$, en un transiluminador a $206 \mathrm{~nm}$ de luz UV, para poder establecer aquellas muestras que contenían la forma especial de F.oxysporum.

Para una más detallada separación y observación, se procedió a correr una electroforesis en PAGE, gel de poliacrilamida al 6\% (19:1) en condición denaturante con
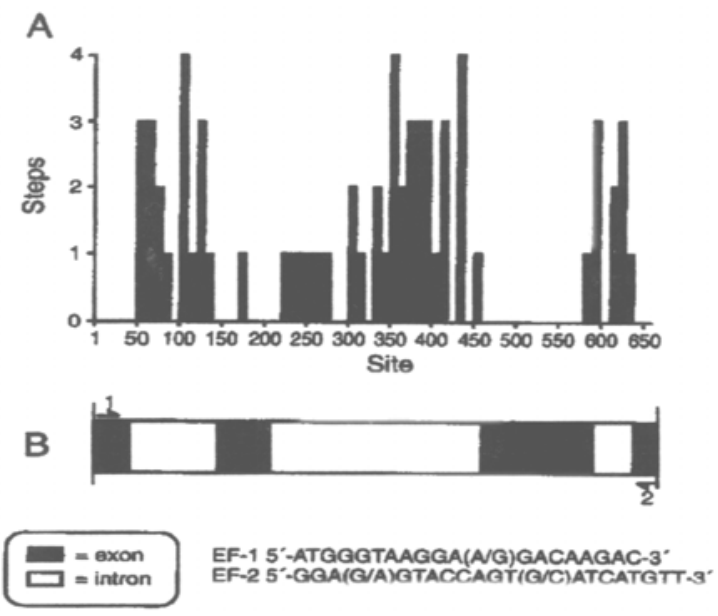

Fig.- 1. (A) Tamaño y variabilidad de la zona de amplificación. (B) Representación gráfica de exones e intrones en el gen EF1-1á (Referencia 21).
7M urea en buffer TBE 0.5X. Condiciones para el PAGE, $50{ }^{\circ} \mathrm{C}$ y 75 watts constantes, por 2 horas. Tinción con nitrato de plata al $2 \%$ (23).

\section{RESULTADOS Y DISCUSION}

El objetivo de este estudio fue diseñar una técnica rápida y eficiente que pudiera detectar las formas patogénicas of f. sp. de F.oxysporum presentes en frutilla, con la finalidad de poder evitar oportunamente el ingreso o salida de estos patógenos cuarentenarios del país.

El proceso de extracción del DNA fue de buena calidad, ya que los DNAg se observaron en buena forma y sin impurezas en casi todas las muestras, salvo para las muestras 8 y 26 en que se observó poca o casi nula presencia de material genético (figura 4). Esto se corroboró con los valores de medición a 260 y $280 \mathrm{~nm}$ que tuvieron una relación promedio de $\mathrm{R}=1,3$ (dato no mostrado). Las cepas crecieron en buena condición y los medios de cultivo fueron los adecuados para permitir el crecimiento de los F.oxysporum presentes en frutilla y otros hospederos (datos no mostrados).

Los resultados de la secuenciación, y posterior análisis de alineamiento por homología, sólo arrojaron datos parciales y de los aproximadamente 650 pares de bases, se pudieron leer cerca de $300 \mathrm{pb}$ muy parcializadas (Fig. 2), y sólo $130 \mathrm{pb}$ de corrido para el análisis de homología mediante el programa DNAssist. Por ello no se puede aventurar alguna conclusión sobre la homología que se pretendió buscar entre F.oxysporum f.sp. fragariae y lycopersicis. De lo que se pudo leer, se detectó una alta homología entre estos dos patógenos, que en los $130 \mathrm{pb}$ que se pudieron comparar, sólo hubo 1 sitio de diferencia a lo publicado en el GeneBank NRRL 26383 (Tabla 2). Posiblemente en las zonas no leídas puede estar la respuesta a los resultados de los respectivos RFLP, que no pudieron dar cuenta cualitativa de los sitios exactos de corte para cada endonucleasa, MseI y MspI.

Todos los DNAg se amplificaron sin dificultades metodológicas, y las muestras que mediante PCR fueron positivas para f.o, tenían los pesos moleculares esperados en los rangos de $650 \mathrm{pb}$, tanto en las 29 cepas obtenidas de las regiones descritas en la Tabla 1, como en las cepas 

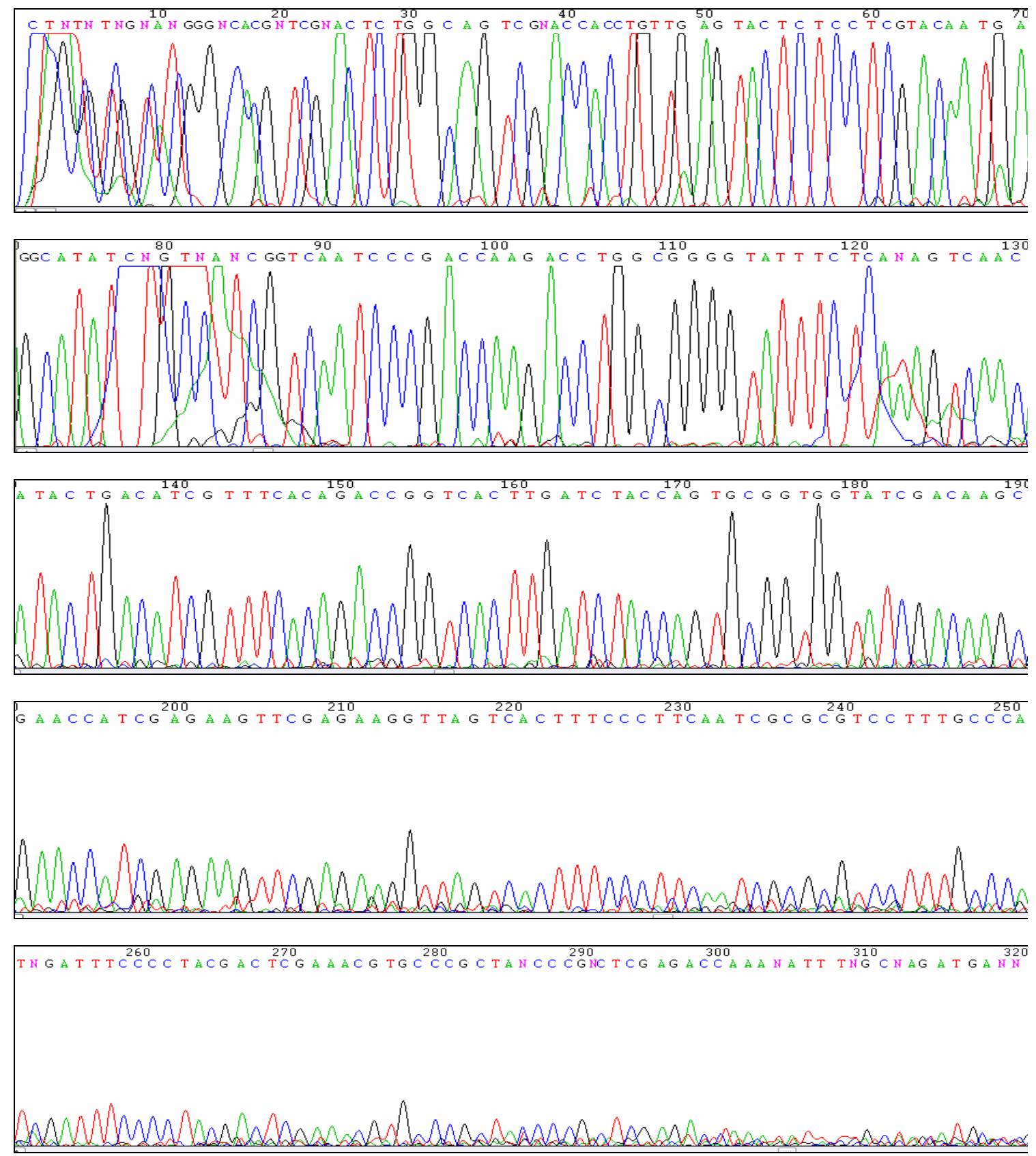

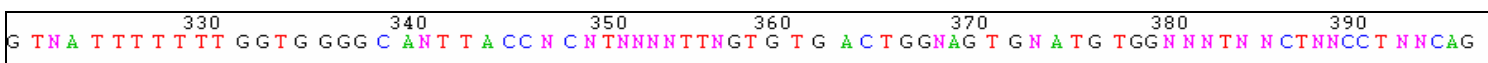

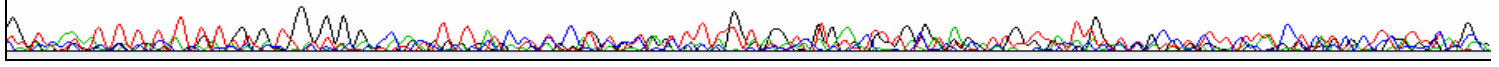

Figura 2 .- Ferograma de resultado de la Secuenciación y alineación del gen EF-1á. 
Tabla 3.- Identificación taxonómica y orígenes de las cepas utilizadas en este estudio. RM (región metropolitana; VIII R, Octava región).

\begin{tabular}{|c|c|c|l|c|}
\hline No $^{\text {Muestra }}$ & Cepa & Origen & Taxón (supuesto) & Hospedero \\
\hline 1 & 1303001 & RM & F. oxysporum f.sp. fragariae & Frutilla \\
\hline 2 & 0834268 & VIII R & F. oxysporum f.sp. fragariae & Frutilla \\
\hline 3 & 08340549 & VIII R & F. oxysporum f.sp. fragariae & Frutilla \\
\hline 4 & 08340550 & VIII R & F. oxysporum f.sp. fragariae & Frutilla \\
\hline 5 & 08340551 & VIII R & F. oxysporum f.sp. fragariae & Frutilla \\
\hline 6 & 0834552 & VIII R & F. oxysporum f.sp. fragariae & Frutilla \\
\hline 7 & 08340553 & VIII R & F. oxysporum f.sp. fragariae & Frutilla \\
\hline 8 & 08340556 & VIII R & F. oxysporum f.sp. fragariae & Frutilla \\
\hline 9 & 08340569 & VIII R & F. oxysporum f.sp. fragariae & Frutilla \\
\hline 10 & 08340571 & VIII R & F. oxysporum f.sp. fragariae & Frutilla \\
\hline 11 & 0834692 & VIII R & F. oxysporum f.sp. fragariae & Frutilla \\
\hline 12 & 0834693 & VIII R & F. oxysporum f.sp. fragariae & Frutilla \\
\hline 13 & 0834696 & VIII R & F. oxysporum f.sp. fragariae & Frutilla \\
\hline 14 & 0834697 & VIII R & F. oxysporum f.sp. fragariae & Frutilla \\
\hline 15 & 0834700 & VIII R & F. oxysporum f.sp. fragariae & Frutilla \\
\hline 16 & 0834701 & VIII R & F. oxysporum f.sp. fragariae & Frutilla \\
\hline 17 & 0834705 & VIII R & F. oxysporum f.sp. fragariae & Frutilla \\
\hline 18 & 0834706 & VIII R & F. oxysporum f.sp. fragariae & Frutilla \\
\hline 19 & 0834707 & VIII R & F. oxysporum f.sp. fragariae & Frutilla \\
\hline 20 & 0834708 & VIII R & F. oxysporum f.sp. fragariae & Frutilla \\
\hline 21 & 080341040 & VIII R & F. oxysporum f.sp. fragariae & Frutilla \\
\hline 22 & 080341043 & VIII R & F. oxysporum f.sp. fragariae & Frutilla \\
\hline 23 & 080341044 & VIII R & F. oxysporum f.sp. fragariae & Frutilla \\
\hline 24 & 080341047 & VIII R & F. oxysporum f.sp. fragariae & Frutilla \\
\hline 25 & 080341053 & VIII R & F. oxysporum f.sp. fragariae & Frutilla \\
\hline 26 & Fof & E.E.U.U & F. oxysporum f.sp. fragariae & Frutilla \\
\hline 27 & Fp & - & & Suelo \\
\hline 28 & Fol & E.E.U.U & F.oxysporum f.sp. lycopersicis & Tomate \\
\hline 29 & Fo & - & & Humano \\
\hline & & & & \\
\hline & & & F.oxysporum & \\
\hline & & & \\
\hline & & &
\end{tabular}

Los DNA genómicos (DNAg), la amplificación y el análisis de restricción de los taxones (supuestos), se observan en las figuras 4, 5 y 6.

control entregadas por el laboratorio nacional del SAG. (Fig. 5). La excepción la constituyó la muestra obtenida de frutilla (SAG), cuyo valor fue algo más bajo al resto, 648 pb aproximadamente (Fig. 8), por lo que se supone un f.o. no patogénico con calidad de secuencia algo distinta a su homólogo de tomate.

Mediante una intensa búsqueda en diversas zonas del gen EF-1á, se encontró un sitio que permite detectar estas formas patogénicas de $\boldsymbol{F}$. oxysporum . Este sitio ubicado en aproximadamente las bases 300 y 350, es una poderosa herramienta para poder diferenciarla de las cepas comunes no patogénicas ampliamente distribuidas (11). Esto se pudo demostrar al digerir con las enzimas MseI y MspI ( Fig. 6), ambas sólo digirieron a la forma especial (figs. 7 y 8), a pesar de ser aplicadas a cepas de Fusarium oxysporum extraídas del mismo hospedador. Los patrones de digestión y amplificación concuerdan con lo propuesto, de tal manera que esta metodología permite discriminar la diferencia entre el patógeno y el no patógeno. 
Tabla 2.- Alineamiento múltiple de secuencias Fusarium oxysporum f.sp. fragariae con Fusarium oxysporum f.sp lycopersici, mediante el programa DNAassist Versión 1.02.

FOL NRRL 26383 translation elongation... 97 CTGGTGGGGTATTTCTCAAAGTCAACATACTG 128 Secuenciado FOF leído 1

AGTCAACATACTG 13

FOL NRRL 26383 translation elongation...

129 ACATCGTTTCACAGACCGGTCACTTGATCTAC 160 Secuenciado FOF leído 14 ACATCGTTTCACAGACCGGTCACTTGATCTAC 45

FOL NRRL 26383 translation elongation... 161 CAGTGCGGTGGTATCGATAAGCGAACCATCGA 192 Secuenciado FOF leído 46 CAGTGCGGTGGTATCGACAAGCGAACCATCGA 77

FOL NRRL 26383 translation elongation... 193 GAAGTTCGAGAAGGTTAGTCACTTTCCCTTCG 224 Secuenciado FOF leído 78 GAAGTTCGAGAAGGTTAGTCACTTTCCCTTCA 109

FOL NRRL 26383 translation elongation... 225 ATCGCGCGTCCTTTGCCCATCGATTTCCCCTA 256 Secuenciado FOF leído 110 ATCGCGCGTCCTTTGCCCAT

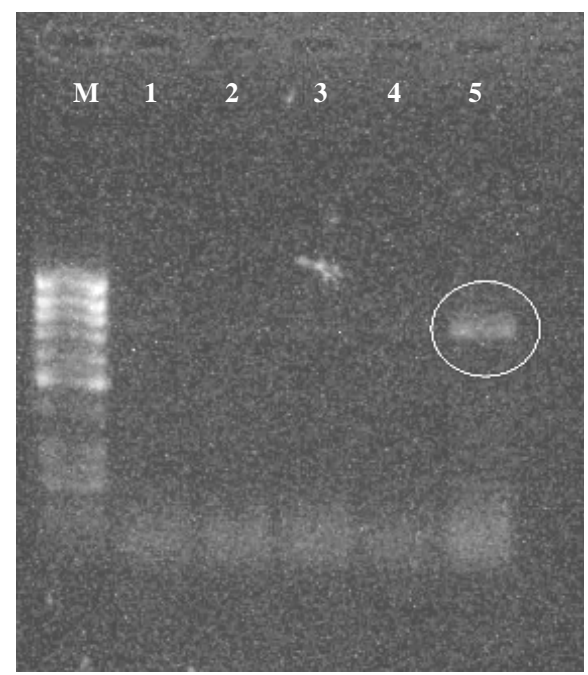

Figura 3; Obtención del gen EF - 1á de Fusarium oxysporum f.sp fragariae de la ATCC mediante la extracción de ADN de la electroforesis en Agarosa 2 $\%$ en TBE 1X. Se observan las muestras amplificadas. Los carriles 1, 2, 3, y 4 indican las muestras problema, diferentes tipos de Fusarium y el $\boldsymbol{F}$. oxysporum f.sp. fragariae (flecha en carril $n^{\circ}$ 5). Carril 1 , patrón de pesos moleculares (pGEM)

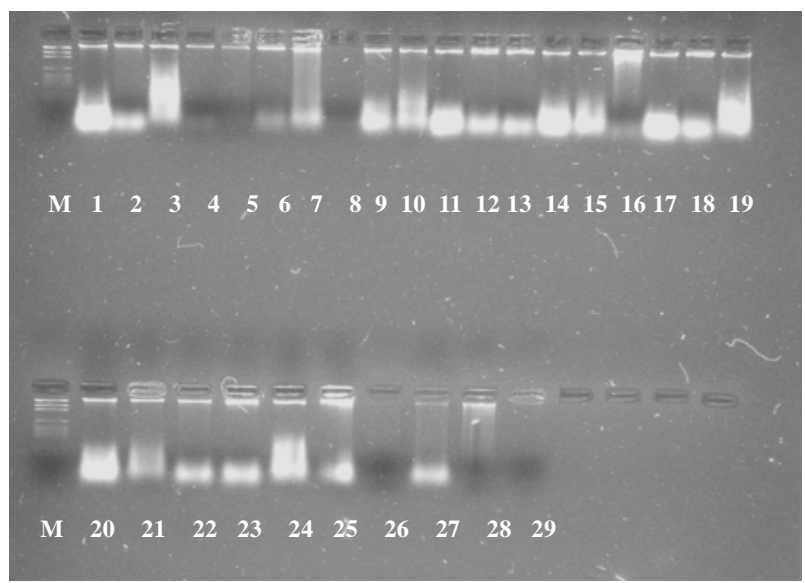

Figura 4. Electroforesis en gel de Agarosa de la extracción de ADN de cada una de las muestras, desde la 1 a la 29, incluidos controles correspondientes de la tabla 1. M es el marcador de peso molecular pGEM (ver tabla de PM).

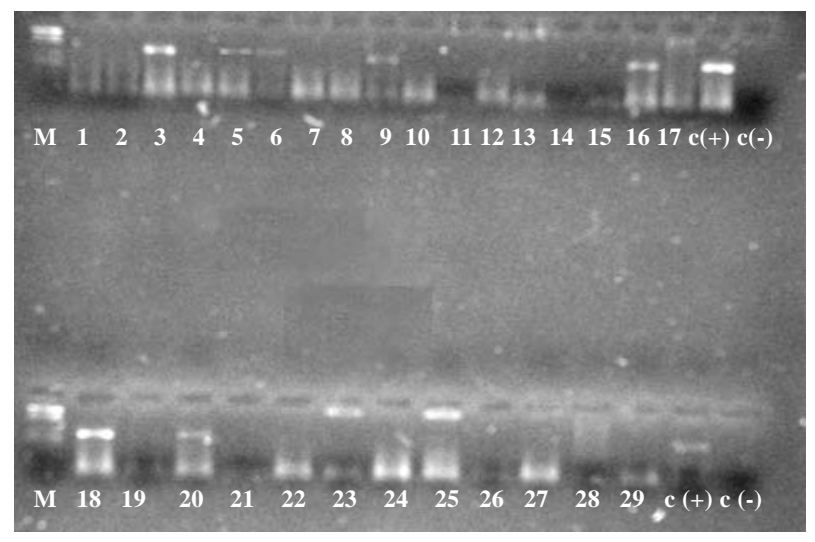

Figura 5. Electroforesis de productos de PCR, obtenidos de cada una de las muestras, desde la 1 a la 29. $M$ es el marcador de peso molecular pGEM.

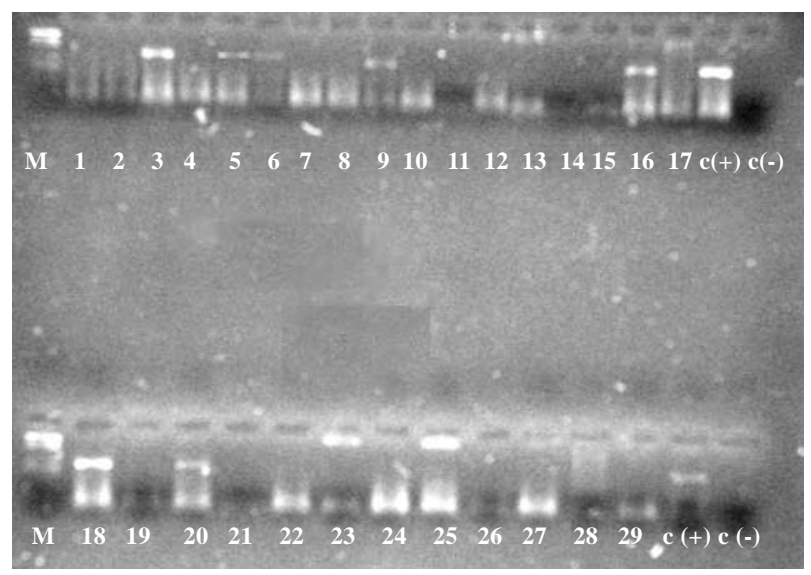

Figura 6.- RFLP en gel de agarosa con productos de digestión con MseI, desde la 1 a la 29. M es el marcador de peso molecular pGEM. 


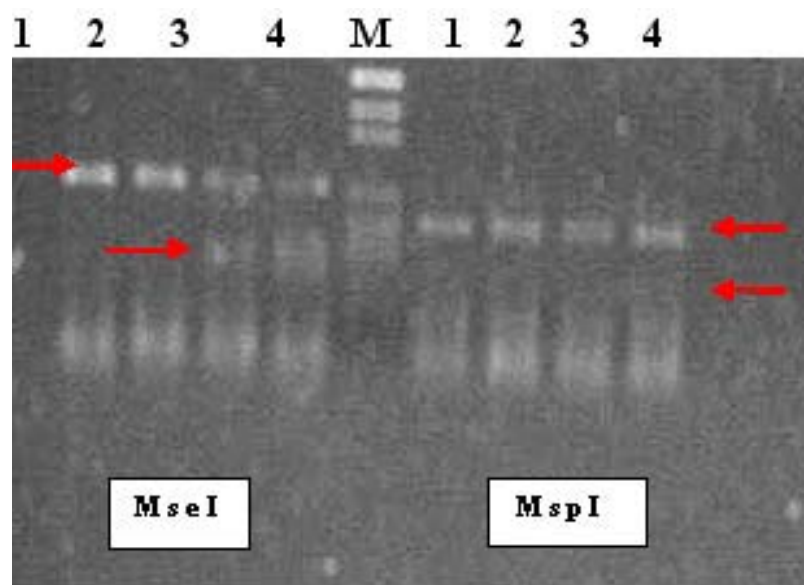

Figura 7.- Gel de Agarosa. Se observan las muestras amplificadas y digeridas con las respectivas enzimas. Los carriles 1 y 3, indican muestras de Fusarium oxysporum extraídos de tomate. Los carriles 2 y 4, muestras de $F$. oxysporum extraídos de frutilla. Para la enzima MseI, la flecha superior indica las muestras amplificadas cuyo PM es de aproximadamente $650 \mathrm{pb}$, y la flecha inferior el producto digerido de 300 y 350 pb (carril 3 y 4). Para la enzima Msp I (Hpa II) la flecha superior indica el amplificado con valores aproximados de $500 \mathrm{pb}$ y la flecha inferior el producto digerido con aproximadamente 200 pb (carril 3 y 4). M, pGEM patrón de pesos moleculares.

El RFLP para Mse I arrojó resultados para las muestras obtenidas de frutilla y tomate respectivamente (Figs. 7 y 8), por lo que se supone $\boldsymbol{F}$. oxysporum formas especiales de esos hospedadores.

El RFLP para Msp I (Hpa II) (Figs. 7y 8), arrojó resultados diferenciales para las muestras 3 y 4 , por lo que se suponen F.oxysporum f.sp fragariae y lycopersicis respectivamente. Como se observa en la figura 8 , la flecha oblicua y la flecha 6 indican las diferencias con el resto de los amplificados, cuyos RFLP respondieron para esta enzima con patrones similares, pero no diferenciadores, es decir valores aproximados de 500 y 175 pb. Hay que hacer notar que los Fusarium f.sp., al parecer tienen patrones cualitativos distintos a sus respectivas formas no patogénicas, ya que como se mencionó anteriormente, la flecha oblicua marca una diferencia cualitativa con respecto al amplificado para esta forma especial (496 pb) y la flecha 6 indica el producto de digestión parcial diferenciador con respecto al resto de los amplificados (173 pb); Por otro lado para el carril 4, se observan digestiones «parciales» (Fig. 8) indicadas con las flechas 7, cuyos valores aproximados son de 275 y 234 pb., esto supone otro criterio adicional de diferenciación de f.o.

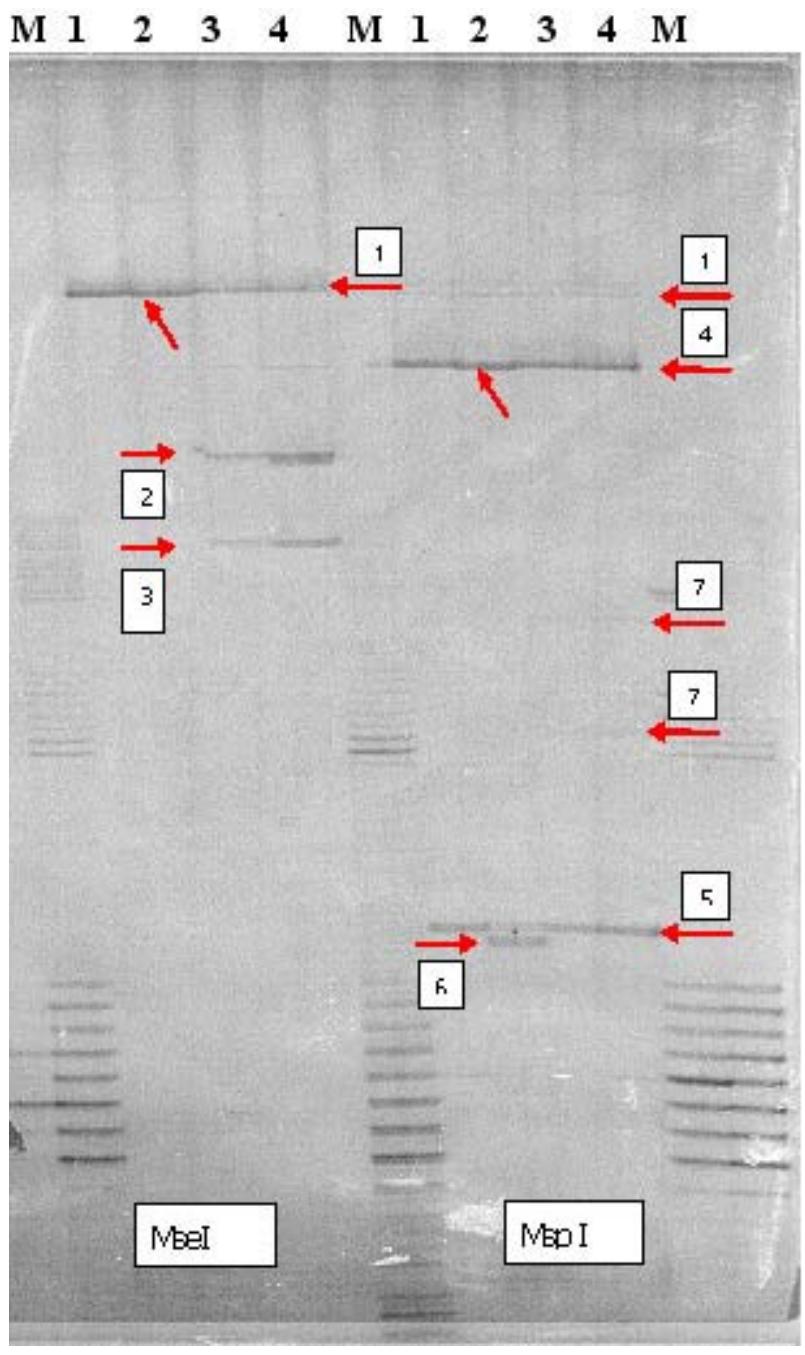

Figura 8. Vista general de digestión con Mse I y Msp I (Hpa II) en gel PAGE denaturante. Se observan las muestras amplificadas y digeridas con las respectivas enzimas. Los carriles 1 y 3, indican muestras de F. oxysporum extraídos de tomate. Los carriles 2 y 4 , muestras de $F$. oxysporum extraídos de frutilla. Las flechas (1) indican los amplificados de todas las muestras con valores de PM cercanos a los $650 \mathrm{pb}$. Las flechas (2) y (3) indican las digestiones con MseI, de aproximadamente 300 y $350 \mathrm{pb}$. Las flechas (4) y (5) indican las digestiones con Msp I (Hpa II) con valores aproximados de 500 y 175 pb. La flecha (6) indica la diferencia de la digestión parcial en el carril 2 (f.o de frutilla) con Msp I (Hpa II), que marca la diferencia con el resto de las muestras con valor menor a 173 pb. Las flechas (7), indican digestión parcial con Msp I para el carril 4 (f.o forma especial de frutilla), con valores de 275 y 234 pb, muestra que se digirió también con MseI. M, marcador de pesos moleculares correspondiente a FFv. 


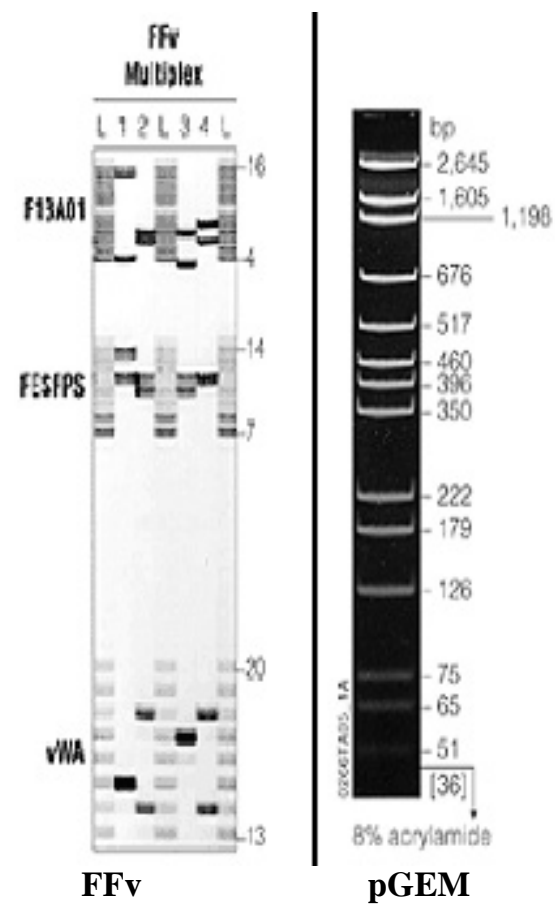

Tabla de Pesos Moleculares. Los respectivos pesos moleculares (PM), se representan en las figuras FFv y pGEM, marcadores estándares de PM, utilizados en este trabajo $(23,24)$. pGEM ${ }^{\circledR}$ DNA Markers consist of 15 DNA fragments ranging in size from $36 \mathrm{bp}$ to $2,645 b p$. These unique markers are prepared by digesting double-stranded pGEM ${ }^{\circledR}-3$ Vector DNA to completion with each of Hinf I, Rsa I and Sin I. After phenol-extraction and ethanol-precipitation, the DNA fragments are resuspended in storage buffer and the 3 digests are mixed. The markers are not intended for use in quantitative analysis. A Blue/Orange Loading Dye, $6 \mathrm{X}$, is provided. Range (bp): $36-2,645$, Number of Bands: 15.

La siguiente tabla se extrajo del manual Promega, en donde se observan los respectivos alelos y PM correspondientes. Cada alelo tiene una diferencia de $4 \mathrm{pb}$, unos con respecto a otros (23).

Multiplex Systen Infermation.

\begin{tabular}{|c|c|c|c|c|c|c|}
\hline $\begin{array}{l}\text { GeneP'int? } \\
\text { STR } \\
\text { Mudfiplex } \\
\text { Cac. } \\
\end{array}$ & $\begin{array}{c}\text { Comprาent } \\
\text { Loci }\end{array}$ & $\begin{array}{c}\text { Alelic } \\
\text { Lacider Size } \\
\text { Range } \\
\text { (bases) }\end{array}$ & $\begin{array}{l}\text { STh Lacder } \\
\text { Allaks } \\
\text { (number of } \\
\text { repests) }\end{array}$ & $\begin{array}{l}\text { Other } \\
\text { Known } \\
\text { Aleles: }\end{array}$ & $\begin{array}{l}\text { K56रे } \\
\text { DNA } \\
\text { Alsles } \\
\text { Sizos } \\
\end{array}$ & $\begin{array}{c}\text { Comments } \\
\text { (ses } \\
\text { balyo) } \\
\end{array}$ \\
\hline $\begin{array}{l}\text { 'FFv } \\
\text { triplex' }\end{array}$ & $\mathrm{F} 13 \mathrm{AO1}$ & $283-331$ & $\begin{array}{c}4,5,6,7,8,9 \\
10,11,12,13, \\
14,15,16\end{array}$ & $3.2,10$ & 53,4 & $1,3,5$ \\
\hline \multirow[t]{2}{*}{$\begin{array}{l}\text { DC6030 } \\
\text { (DC6031) }\end{array}$} & FESFPS & $222-250$ & $\begin{array}{c}7,8,9,10,11, \\
12,13,14 \\
\end{array}$ & None & 12,10 & 1,5 \\
\hline & VWIA & $139-167$ & $\begin{array}{l}13,14,15,16, \\
17,18,19,20\end{array}$ & 1121 & 16,16 & 1,5 \\
\hline
\end{tabular}

Las muestras 1 y 2, no presentaron patrones de corte diferenciadores para los respectivos RFLP, por lo que se suponen $\boldsymbol{F}$. oxysporum no especificado (N.E.), aún teniendo patrones similares de PM entre ellas en los amplificados, ello podría indicar que son $\boldsymbol{F}$. oxysporum provenientes de los mismos hospedadores de las respectivas formas especiales observadas, es decir, la muestra 2 puede ser la forma no patogénica de un $\boldsymbol{F}$. oxysporum proveniente de frutilla, y 1 puede ser la forma no patogénica de uno proveniente de tomate. Por lo que se concluye que las muestras 3 y 4 corresponden a las formas especiales para lycopersicis y fragariae, respectivamente.

Aunque el gen EF- $1 \alpha$ no sea parte de los mecanismos genéticos que expliquen las diferencias patogénicas entre formas especiales y cepas no-patogénicas, de igual manera se puede decir que la técnica propuesta es una excelente herramienta para detectar $\boldsymbol{F}$. oxysporum f. sp lycopersici y F. oxysporum f.sp fragariae, proponiéndose como una metodología sensible y altamente eficiente, para aplicarla en cualquier análisis de búsqueda de estos patógenos cuarentenarios.

\section{AGRADECIMIENTOS}

Al Dr. Eduardo Piontelli del laboratorio de Micología de la Escuela de Medicina de la Universidad de Valparaíso, y al Sr. Eduardo Chavez del Sub departamento de Laboratorios y estación Cuarentenaria Agrícola, del Servicio Agrícola y Ganadero (SAG) de lo Aguirre, Santiago, por sus respectivas colaboraciones y aportes de cepas al presente trabajo.

\section{REFERENCIAS}

1.-Apablaza, G. (2000). Patología de cultivos, epidemiología y control holístico. Ediciones Universidad Católica de Chile.

2.- Baayen, R., P. (2000). Diagnosis and detection of host-specific forms of Fusarium oxysporum. Bulletin OEPP/EPPO 30:489-491

3.- Edel, V.; Steinberg, C.; Avelange, I.; Laguerre, G .; Alabouvette, C. (1995). Comparison of three molecular methods for the characterization of Fusarium oxysporum Strains. Phytophatology 85: 579-585

4.- Fernández, D.; Ouinten,M.; Tantaoui, A.; Geiger, J.P.; Daboussi, M. J.; Langin, T. (1998). Fot 1 Insertions in the Fusarium oxysporum f. sp.albedinis genome provide diagnostic PCR targets for detection of the date palm pathogen. Applied Environmental. Microbiology 64:633-636

5.- Gale, L. R.; Katan, T. \& Kistler, H.C. (2003). The probable center of origin of Fusarium oxysporum f. sp. lycopersici VCG 0033. Plant Dis. 87. XXXXX

6.- Hua-Van, A.; Langin, T. \& Daboussi, M.J. (2001). Evolutionary history of the impala transposon in Fusarium oxysporum. Mol. Biol. Evol. 18:1959-1969 
7.- Jaeger, M.; Carroll,N.; Choudhury, S.; Dunlop, A.; Towler, H.; Matheson, M.; Adamson, P.; Okhravi, N.; Lightman, S. (2000). Rapid detection and identification of Candida, Aspergillus, and Fusarium species in ocular samples using nested PCR. Journal of Clinical Microbiology 38. 2902-2908.

8.- Jarvis, W. R. \& Shoemaker, R. A. (1978). Taxonomic status of Fusarium oxysporum causing foot and root rot of tomato. Phytopathology 68:1679-1680

9.- Katan, T. (1999). Current status of vegetative compatibily groups in Fusarium oxysporum. Phytoparasitica 27:51-64

10.- Khalid, L.; Pérez-Espinoza, A.; Pineda, M. \& Ruiz-Rubio, M. (1996). Purification and characterization of tomatinase from Fusarium oxysporum f. sp. lycopersici. Applied Environmental Microbiology 62:1604-1609

11.- Kistler, H. C. (1997). Genetic diversity in the plant pathogenic fungus Fusarium oxysporum. Phytopathology 87:474-479

12.- Liu, D.; Coloe,S.; Baird,R. \& Pedersen, J. (2000). Rapid minipreparation of fungal DNA for PCR. Journal of Clinical Microbiology 38: 471

13.- Menzies, J. G. \& Jarvis, W. R. (1994). The infestation of tomato seed by Fusarium oxysporum f. sp. radicis-lycopersici. Plant Pathology 43:378-386

14.- Namiki, F.; Shiomi, T.; Kayamura, T \& Tsuge, T. (1994). Characterization of the formae speciales of Fusarium oxysporum causing wilts of cucurbits by DNA fingerprinting.with nuclear repetitive DNA sequences. Applied Environmental. Microbiology 60: 2684-2691

15.- Nelson, P. E.;Toussoun, T. A. \& Marasas, W. F. O. (1983). Fusarium species: an illustration manualfor identification. University Park, Pennsylvania State University Press, Pensylvania, USA.

16.- O'Donnell, K.; Kistler, H.K. \& Cigelnik, E. (1998). Multiple evolutionary origins of the fungus causing Panama disease of Banan: Concordant evidence from nuclear and mitochondrial gene genealogies. Proc. Natl. Sci. USA 95:2044-2049
17.- *Plyler, T. R.; Simone, G. W.; Fernández, D. \& Kistler, H. C. (1999). Rapid detection of the Fusarium oxysporum lineage containing the Canary Island date palm wilt pathogen. Phytopathology 89:407-413

18.- Vakalounakis, D. J. \& Fragkiadakis,G. A. (2000). Genetic variation among Fusarium oxysporum isolates from cucumber. Bulletin OEPP/EPPO 30:175-177

19.- Veloso, M. M.; Melo, M. E.; Jorge-Silva, L. \& Bravo, M. (2000). Genetic Diversity in Fusarium oxysporum f. sp. melonis. Bulletin OEPP/EPPO 30:195-197

20.- Wang-Ching, H. \& Wen-Hsiung, K. (1997). A simple method for obtaining single-spore isolates of fungi. Bot. Bull. Acad. Sin. 38: 41-44.

21. - O'Donnell, K.; Kistler, H.C.; Cigelnik, E. \& Ploetz, R.C. (1998). Multiple origins of the fungus causing Panama disease of banana: concordant evidence from nuclear and mitochondrial gene genealogies. Proc. Natl. Acad. Sci. USA 95:2044-2049

22.- Kim Y.; Hutmacher, R.B. \& Davis, R.M. (2005). Characterization of California Isolates of Fusarium oxysporum f.sp. vasinfectum. Plant Disease 89:366-372

23.- Technical Manual No.D004 GenePrint ${ }^{\circledR}$ STR Systems (Silver Stain Detection), (2005). Promega Corp. 2800 Woods Hollow Road Madison, WI 53711-5399 USA, Toll Free in USA 800-356-9526, Telephone:608274-4330, Fax 608-277-2516 www.promega.com

24.- pGEM $^{\circledR}$ DNA Markers, Cat.\# G1741, ( ) (2005). Promega Corporation. All rights reserved.

25.- Ortoneda,M.; Guarro,J.; Madrid,M.; Caracuel, Z.; Roncero, M.I.; Mayayo, E.; Di Pietro, A. (2004). Fusarium oxysporum as a Multihost Model for the Genetic Dissection of Fungal Virulence in Plants and Mammals. INFECTION AND IMMUNITY. 72:1760-1766

26.- Nelson, P.; Tousson, T.A. \& Marasas, W.F.O. (1983). Fusarium species. An illustrated manual for identification. The Pennsylvania State University Press. 